\title{
La anatomía patológica en el Perú: una especialidad subestimada en el manejo multidisciplinario
}

\section{Pathology in Peru: an underestimated specialty in multidisciplinary management}

Correspondencia Karina Patino-Calla karinapc55@gmail.com

Recibido: 04/04/2017 Aprobado: 26/04/2017

Citar como: Patiño-Calla K Yabar Berrocal A. La anatomía patológica en el Perú: una especialidad subestimada en el manejo multidisciplinario [carta]. Acta Med Peru. 2017;34(2):154-5

\author{
Karina Patiño-Calla ${ }^{1,2, a}$, Alejandro Yabar Berrocal ${ }^{1,3, b}$ \\ 1 Hospital Nacional Edgardo Rebagliati Martins, EsSalud. Lima, Perú. \\ 2 Facultad de Medicina Humana, Universidad Nacional Mayor de San Marcos. Lima, Perú. \\ 3 Facultad de Medicina Humana, Universidad Ricardo Palma, Lima, Perú. \\ a Médico Residente, b Jefe del Departamento de Anatomía Patológica
}

Sr. Editor:

En nuestro país, el especialista en anatomía patológica realiza una actividad desconocida o poco entendida, incluso entre los colegas médicos, quienes suelen confundir su actividad con la de otros médicos especialistas como los patólogos clínicos. Se suele asociar a la actividad del anatomopatólogo con la realización de necropsias ${ }^{[1]}$, que sólo es una parte de la práctica médica; pues involucra además el estudio de los cambios morfológicos ocasionados en las células, tejidos y órganos a niveles macroscópico, microscópico (biopsias escisionales, incisionales, resección de piezas quirúrgicas) y actualmente, con el advenimiento de nuevos medios diagnósticos, molecular y citogenético ${ }^{[2]}$.

El trabajo de esta especialidad es de gran relevancia. Los diagnósticos que se realizan son la clave y base sobre la que se fundamentan diversos tratamientos y proyecciones pronósticas. Pocos médicos definen tratamientos específicos sin tener antes el informe diagnóstico firmado por el anatomopatólogo ${ }^{[2]}$; por ello, se define a esta especialidad como la piedra angular en la hoy denominada "medicina personalizada" [3]. Debido a la gran importancia de su actividad todos los centros hospitalarios cuentan con áreas de anatomía patológica.

Consecuencia del desconocimiento de lo que la anatomía patológica abarca, colegas de otras especialidades tienen la errónea idea de que los patólogos son meros microscopistas que reportan y diagnostican misteriosamente, subestimando sus conocimientos, capacidad de asociación y la necesidad de información complementaria requerida para un adecuado diagnóstico. Siendo este un concepto arcaico para la medicina actual, ya que el aporte y asociación de la información clínica, radiológica, de laboratorio, entre otras, es necesaria para un manejo multidisciplinario en beneficio del paciente; es indispensable un aporte suficiente de información de buena calidad ya que pocas veces el anatomopatólogo tiene contacto con el paciente ${ }^{[3]}$.

Con ello observamos que en la práctica médica esta especialidad es menospreciada e incluso minimizada por otras, subestimando la preparación e incluso los conocimientos básicos en medicina ${ }^{[4]}$, desestimando la necesidad de reuniones multidisciplinarias con la intervención de estos especialistas para conocer su opinión desde su punto de vista.

En conclusión, las actividades que realiza el médico anatomopatólogo son de gran relevancia institucional y son eje en el proceso diagnóstico. Por ello, debemos de exhortar a los gestores en salud de nuestro país dar la relevancia suficiente a esta especialidad, proponiendo un manejo multidisciplinario de los pacientes, realizando reuniones clínicas continuas en las cuales los anatomopatólogos puedan aportar 
y opinar para afinar diagnósticos y tratamientos. Así mismo, se debe de impedir todo tipo de interferencias e intrusismo basados en falsas o imprecisas interpretaciones del uso de las nuevas tecnologías; las que son de mucha utilidad en diversas especialidades, entre ellas la anatomía patológica ${ }^{[5]}$.

\section{REFERENCIAS BIBLIOGRÁFICAS}

1. Vargas M, Rodríguez D. Importancia del estudio histopatológico en la determinación de las causas de defunción de autopsias médico legales cuya manera de muerte se clasificó como natural. Med Leg Costa Rica. 2015;32(1):5-23.

2. Bautista V, Moreno ER. Principios básicos para llevarse bien con su patólogo. An Med Asoc Med Hosp ABC. 2013;58(4):281-4

3. Gonzalez R. Mirando al futuro: una patología para el siglo XXI. Rev Esp Patol. 2013;46(3):137-8.

4. Mayayo E. La proyección latinoamericana de la patología española. Rev Esp Patol. 2006;39(4):199-200.

5. Mayayo E. ¿Qué pasaría si desaparecieran los servicios de patología de nuestros hospitales? Rev Esp Patol. 2016;49(3):137-8.

\section{Las ediciones anteriores de Acta Médica Peruana están disponibles en:}

\section{www.scielo.org.pe}

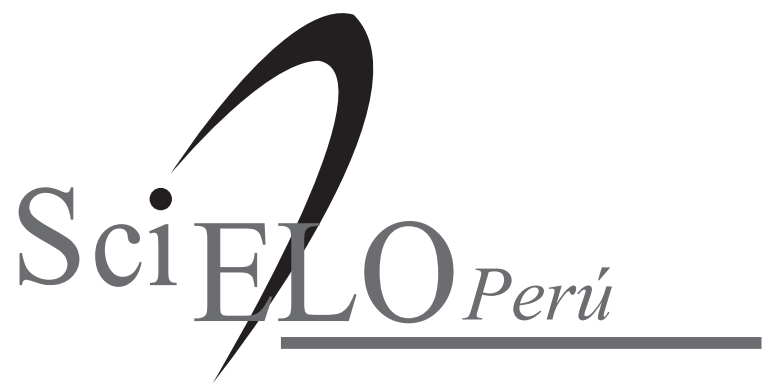

